\title{
DESIGN AND ANALYSIS OF CONNECTING ROD
}

\author{
Mr.K. Vinay Kumar Reddy ${ }^{01}$, D. Ravi Teja ${ }^{02}$, K. Narendar Reddy ${ }^{03}$, K. Madhusudhan ${ }^{04}$. \\ Department of Mechanical Engineering, Guru Nanak Institute of Technology, Hyderabad.
}

\begin{abstract}
:
The connecting rod is a major link inside of the combustion engine. It connects the piston to the crankshaft and is responsible for transferring the power from the piston to the crankshaft. It has to work on higher r. p.m. because of which it has to bear severe stresses which make its design vital for the internal combustion engine. In this paper, a connecting rod for two-wheeler is designed by analytical method. On the basis of that the design a physical model is created in Solid Works. Structural system of the connecting rod has been analysed by using Analysis. With the use of Analysis various stresses are calculated for the loading conditions using Analysis software ANSYS WORKBENCH 14.5. The same work is carried out for the Aluminium alloy. The obtained results (Stresses, shear stress, fatigue life based on results concluded the suitable material for connecting are compared. on the basis of various performances with considerable.
\end{abstract}

KEY WORDS: Connecting Rod, Aluminium Alloy, Solid Works.

\section{INTRODUCTION}

\subsection{CONNECTING ROD}

A connecting rod is the part of a piston engine which connects the piston to the crankshaft. Together with the crank, the connecting rod converts the reciprocating motion of the piston into the rotation of the

crankshaft. The connecting rod is required to transmit the compressive and tensile forces from the piston. In its most common form, in an internal combustion engine, it allows pivoting on the piston end and rotation on the shaft end.

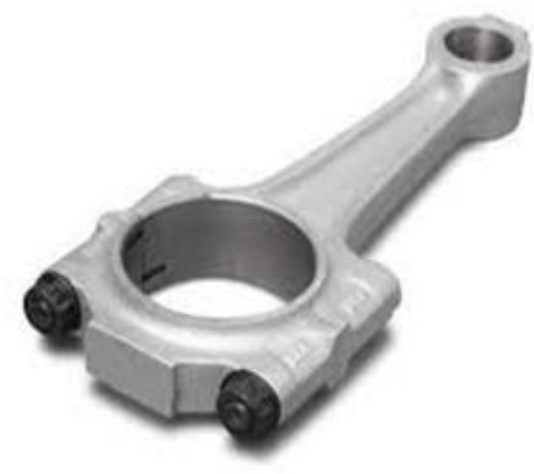

A Connecting Rod can be of two types H-beam or Ibeam or a combination of both. They are used respectively depending on their field of application or use. An I-beam is both light weight and strong, but the type of material used limits it's capacity to handle load. Whereas a H-beam can handle much more stress without bending. So, they are used in high power engines.

The function of connecting rod is to transmit the thrust of the piston to the crank shaft, and as the result the reciprocating motion of the piston is translated into rotational motion of the crank shaft. Connecting rod has three main zones: the piston pin end, the centre shank and the big end. The piston pin end is the small end, the crank end is the big end, and the centre shank is of I cross section. The connecting rods are subjected to a complex state of loading therefore, durability of this component is of critical importance. Due to these factors, the connecting rod has been the topic of research for the different aspects such as the production technology, materials, stress analysis etc.

This analysis used the maximum load which was measured theoretically and the maximum stresses at variable loads are found experimentally which suggests the reduction of the inertia load of the connecting rod mass. Connecting rods must have the highest possible rigidity at the lowest weight.

Besides its lower density, it has a high resistance to corrosion under the majority of service conditions. In modern automotive internal combustion engine, the connecting rods are most usually made of aluminium and steel. In high performance engines such as two wheelers the connecting rod is mostly made aluminium alloys due to high strength to weight ratio.

Reasons For Using Aluminium: Our choice of metal for this project is Aluminium alloy. This metal is preferred due to its light weight and low cost. The choice of the metal used also depends on the type of requirement and preference. Metals such as Aluminium are lightweight and strong and costless as compared to other materials like Titanium that are stronger but much costlier. One of the most common usages is of Steel and its alloys.

Beam Types: An I-beam is both light weight and strong, but the type of material used limits.

It's capacity to handle load. Whereas a H-beam can handle much more stress without bending. So, they are used in high power engines. A combination of both is also used in some cases. 
Design Process: Solid Works software is used for the designing process. Using Solid Work Parametric a design is readied for the connecting rod with the given dimensions. For analysing the design created it is imported in to ANSYS software for further analysis of the key factors such as as stress, strain, factor of safety, deformation, fatigue analysis and working cycle.

\section{LITERATURE SURVEY}

This section includes the literature survey of earlier research work made by various researchers on connecting rod. Various researchers presented the different techniques in the development of connecting rod and their optimization. This section presents the summary of these research works.

The connecting rod has been the topic of research for different aspects such as production technology, materials, performance simulation, fatigue, etc. For the current study, it was necessary to investigate finite element modelling techniques, optimization techniques, developments in production technology, new materials, fatigue modelling, and manufacturing cost analysis. This brief literature survey reviews some of these aspects.

Webster et al. (1983) performed threedimensional finite element analysis of a high diesel engine connecting rod. For this analysis they used the maximum compressive load, which was measured experimentally, and the maximum tensile load which is essentially the inertia load of the piston assembly mass. The load distributions on the piston pin end and crank end were determined experimentally. They modelled the connecting rod cap separately, and also modelled the bolt pretension using beam elements and multi point constraint equations.

In a study reported by Repgen (1998), based on fatigue tests carried out on identical components ma de of powder metal and C-70 steel (fracture splitting steel), he notes that the fatigue strength of the forged steel part is $21 \%$ higher than that of the powder metal component. He also notes that using the fracture splitting technology results in a $25 \%$ cost reduction over the conventional steel forging process. These factors suggest that a fracture splitting material would be the material of choice for steel forged connecting rods. He also mentions two other steels that are being tested, a modified micro-alloyed steel and a modified carbon steel. Other issues discussed by Repgen are the necessity to avoid jig spots along the parting line of the rod and the cap, need of consistency in the chemical composition and manufacturing process to reduce variance in microstructure and production of near net shape rough part.

Asadi, (2010) developed detailed load analysis under service loading conditions was performed for connecting rod and the conclusions can be drawn from this study as follows the maximum pressure stress was obtained between pin end and rod linkage and the maximum tensile stress was obtained in lower half of pin end.

H.B. Ramani has do Analysis of Connecting Rod under Different Loading Condition Using ANSYS Software. In spite of the great power of FEA, the disadvantages of computer solutions must be kept in mind when using this and similar methods, they do not necessarily reveal how the stresses are influenced by important problem variables such as materials properties and geometrical features, and errors in input data can produce wildly incorrect results that may be overlooked by the analyst.

Pravardhan S. Shenoy and Ali Fatemi (2005) carried out the dynamic load analysis and optimization of connecting rod. The main objective of this study was to explore weight and cost reduction opportunities for a production forged steel connecting rod. Typically, an optimum solution is the minimum or maximum possible value the objective function could achieve under a defined set of constraints. The weight of the connecting rod has little influence on the cost of the final component. Change in the material, resulting in a significant reduction in machining cost, was the key factor in cost reduction.

Shahrukh Shamim studied finite element analysis of connecting rod used in single cylinder four stroke stress analysis is conducted on connecting rod made up of two different materials viz. E-glass/Epoxy and Aluminium composite reinforced with Carbon nano tubes. Modelling and comparative analysis of connecting rod is carried out in commercially used FEM software ANSYS 14.0

Dr. B.K. Roy carried out the research on Design Analysis and Optimization of Various Parameters of Connecting Rod using CAE Software's. Various designs of connecting rod have been analysed in this report and finally an optimal design has been selected for Finite Element Analysis. Using ANSYS-12.0 Workbench and CATIA V5R19, Various results are found out and compared with the existing results. It has been found out that the study presented here has come up with better results as well as safe design of connecting rod under permissible limits of various parameters and safe stresses.

$$
\begin{aligned}
& \text { Kuldeep B "Analysis and optimization of } \\
& \text { connecting } \\
& \text { rod using ALFA Sic }
\end{aligned}
$$
composites". Generally, connecting rods are manufactured using carbon steel and in recent days Aluminium alloys are finding its application in connecting rod. In this work connecting rod is replaced by Aluminium based composite material reinforced with silicon carbide and fly ash. And it also describes the modelling and analysis of connecting rod. FEA analysis was carried out by considering two materials. The parameter like von misses stress, von misses strain and displacements were obtained from ANSYS software. 


\section{ITHODOLOGY AND PROBLEM STATEMENT}

\subsection{Methodology}

Step 1: Collecting information and data related connecting rod.

Step 2: A fully parametric model of the connecting rod is created in Solid Works software.

Step 3: Model obtained in Step 2 is analysed using ANSYS 14.5(workbench), to obtain vonmissies stress and shear stresses.

Step 4: Manual calculations are done.

Step 5: Finally, we compare the results obtained from ANSYS.

\subsection{Problem Statement}

- Connecting rod with Aluminium Alloy and its behaviour study by FEM analysis.

For the analysis of I.C. Engine connecting rod, the most critical area is considered. The objective of the present work is to determine the stresses in critical areas, the spots in the connecting rod where there are more chances of failure. The different dimensions of the connecting rod for Aluminium alloy is calculated through analytical method. Calculated loads are applied at one end and the other end kept fixed. Finally, both results are compared for performance, various stresses, weight, life cycles, fatigue life, heat flux etc. and best alternative is defined. Connecting rod model was created in SOLID WORKS. After that the model is imported in ANSYS 14.5 (Workbench) for analysis.

\subsection{Objectives}

The following are the main objectives of the present work:

SolidWorks currently markets several versions of the SolidWorks CAD software in addition to Drawings, a collaboration tool, and DraftSight, a 2D CAD product.

SolidWorks is a solid modeler and utilizes a parametric feature-based approach which was initially developed by PTC (Creo/Pro-Engineer) to create models and

SolidWorks does not support macOS. money assemblies. The software is written on Parasolid-kernel.

A static two types design study is created for the connecting rod, to reach design optimization by SOLIDWORKS simulation, A bearing load the design.
- $\quad$ To design connecting rod by using Solid Works work bench with geometry given below data.

- $\quad$ To determine von-misses stresses and shear stresses.

- $\quad$ To identify suitable alloy for the fabrication based on results obtained from finite element analysis and analytical method.

\section{DESIGN AND ANALYSIS OF CONNECTING ROD}

\subsection{Design and development of Connecting Rod in SOLID WORKS}

SolidWorks is a solid modelling computeraided design (CAD) and computer-aided engineering (CAE) computer program published by Dassault Systems, that runs primarily on Microsoft Windows. While it is possible to run SolidWorks on an Intel-based Mac with Windows installed, the application's developer recommends against this. equations added to the lower small pin contact surface, the upper big end was fixed. The connecting rod solid meshed shown in Figure 4(b), the static analyses was carried out and von Mises, deformation of connecting rod were studied for steel alloys and aluminum alloy. While for the fatigue loads are repetitive or fully reversal cyclic loads with constant amplitude.

SolidWorks is a 3D solid modelling package which allows users to develop full solid models in a simulated environment for both design and analysis. In SolidWorks, the sketch ideas and experiment with different designs to create 3D models. SolidWorks is used by designers, engineers, and other professionals to produce simple and complex parts, assemblies and drawings. Designing in a modelling package such as SolidWorks is beneficial because it saves time, effort, and

\subsection{Design of a Connecting rod}

A connecting rod is a machine member which is subjected to alternating direct compressive and tensile forces. Since the compressive forces are much higher than the tensile force, therefore the cross-section of the connecting rod is designed as a strut and the Rankine formula is used. A that would otherwise be spentconnecting rod subjected to an axial load $\mathrm{W}$ may buckle with $\mathrm{x}$-axis as neutral axis in the plane of motion of the connecting rod, $\{$ or $\}$ y-axis is a neutral axis. The connecting rod is considered like both ends hinged for buckling about $\mathrm{x}$-axis and both ends fixed for buckling about y-axis. A connecting rod should be equally strong in buckling about either axis.

Let,

$\mathrm{A}=$ cross sectional area of the connecting rod. $\mathrm{L}=$ length of the connecting rod. $\mathrm{c}=$ compressive yield stress.

Wcr =crippling or buckling load. 
I $\mathrm{xx}=$ moment of inertia of the section about $\mathrm{x}$-axis

I yy $=$ moment of inertia of the section about y-axis

$\mathrm{K} \mathrm{xx}=$ radius of gyration of the section about $\mathrm{x}$-axis

$\mathrm{K}$ yy $=$ radius of gyration of the section about $\mathrm{y}$ - axis $\mathrm{D}=$ Diameter of piston

$\mathrm{r}=$ Radius of crank Rankine formula $=$

$(\mathrm{Ixx}=4 \mathrm{Iyy})$

B. Pressure Calculation for $150 \mathrm{cc}$ Engine

Engine type: Air cooled 4-stroke

Bore $\times$ Stroke $(\mathrm{mm})=57 * 58.6$

Displacement $=149.5 \mathrm{cc}$

Max. Power $=13.8 \mathrm{bhp}$ at the rate of $8500 \mathrm{rpm}$

Max. Torque $=13.4 \mathrm{Nm}$ at the rate of

$6000 \mathrm{rpm}$

Compression Ratio $=9.35 / 1$

Density of Petrol [C8H18] $=737.22 \mathrm{~kg} / \mathrm{m} 3$

Temperature $=60 \mathrm{~F}=288.855 \mathrm{~K}$

Mass $=$ Density $\times$ Volume $=0.11 \mathrm{Kg}$ Molecular Weight of Petrol $=114.228 \mathrm{~g} / \mathrm{mole}$

From Gas Equation,

$\mathrm{PV}=\mathrm{Mrt}$

$\mathrm{R}=\mathrm{R} * \mathrm{Mw}=8.3143 / 114.28=72.76$

$\mathrm{P}=(0.11 * 72.786 * 288.85) / 149.5 \mathrm{E} 3 \mathrm{P}=15.469 \mathrm{MPa}$.

C. Design Calculation for Carbon Steel

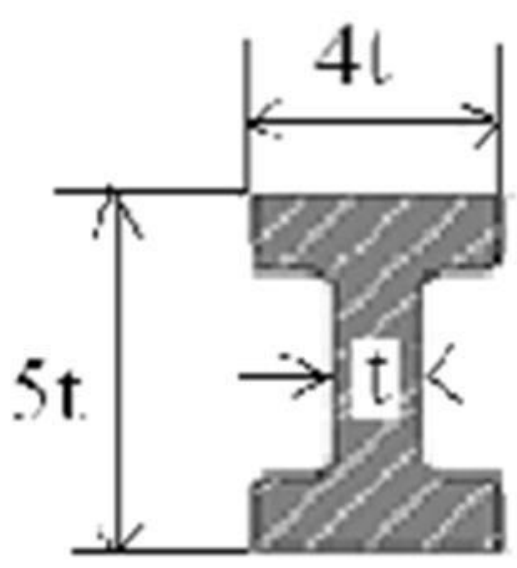

Thickness of flange $\&$ web of the section $=\mathrm{t}$

Width of section $(B)=4 t$

The standard dimension of I-SECTION is shown in the Fig. 3.

Height of section $\mathrm{H}=5 \mathrm{t}$

Area of section $A=2\left(4 t^{*} t\right)+3 t^{*} t=11 t 2$ MI of section about $x$ axis:

I xx $=1 \backslash 12(4 t(5 t) 3-3 t(3 t) 3)=419 \backslash 12 t 4$

MI of section about y axis:

I yy $=(2+1 \backslash 12 t(4 t) 3+1 \backslash 12(3 t) t 3)=131 \backslash 12 t 4$

$\mathrm{I} x \mathrm{x} / \mathrm{I}$ yy $=3.2$

Length of connecting rod $(\mathrm{L})=2$ times the stroke $\mathrm{L}=117.2$ $\mathrm{mm}$

Buckling load $=$ maximum gas force $\times$ F.O.S $\mathrm{Wb}=$ $\left(\sigma c^{*} \mathrm{~A}\right) / 1+\left[\mathrm{a}^{*}(\mathrm{LlK} \mathrm{xx}) 2\right]=37663 \sigma \mathrm{c}=$ compressive yield stress $=415 \mathrm{MPa}$

$\mathrm{k} \mathrm{xx}=\mathrm{I} \mathrm{xx} \backslash \mathrm{A} \mathrm{kxx}=1.78 \mathrm{t} \mathrm{A}=\sigma \mathrm{c} / \square 2 \mathrm{E} \mathrm{a}=$

0.0002

By substituting $\sigma \mathrm{c}, \mathrm{A}$, a, L, kxx 4565t4 -

$37663 \mathrm{t} 2-81639.46=0 \mathrm{t} 2=10.03 \mathrm{t}=3.2 \mathrm{~mm}$

Width of section $B=4 \mathrm{t}=12.8 \mathrm{~mm}$

Height of section $\mathrm{H}=5 \mathrm{t}=16 \mathrm{~mm}$

Area $\mathrm{A}=11 \mathrm{t} 2=112.64 \mathrm{~mm} 2$

Radius of $\operatorname{crank}(\mathrm{r})=$ stroke length $/ 2=58.6 / 2=29.3$

Maximum force on the piston due to pressure $\mathrm{Fl}$

$=\pi / 4 * \mathrm{D} 2 * \mathrm{p}=(\pi / 4) *(57) 2 * 15.469=39473.16 \mathrm{~N}$

Maximum angular speed $\mathrm{Wmax}=$

$[2 \pi \mathrm{Nmax}] / 60=[2 \pi * 8500] / 60,=2=768 \mathrm{rad} / \mathrm{sec}$

Ratio of the length of connecting rod to the radius of crank $\mathrm{N}=$ $\mathrm{L} / \mathrm{r}=112 /(29.3)=3.8$

Maximum Inertia force of reciprocating parts

$\mathrm{F}$ im $=\mathrm{Mr}(\mathrm{Wmax}) 2 \mathrm{r}(\cos \theta+\operatorname{COS} 2 \theta \mathrm{n})(\mathrm{Or})$

$\mathrm{F} \mathrm{im}=\mathrm{Mr}(\mathrm{Wmax}) * 2 \mathrm{r}(1+1 / \mathrm{n})=0.11 \mathrm{x}(768) 2 *(0.0293) *$ $(1+(1 / 3.8))$

$\mathrm{F}$ im $=2376.26 \mathrm{~N}$

Inner diameter of the small end $\mathrm{d} 1=\mathrm{fg} / \mathrm{Pb} 1 * 11=$ $6277.167 / 12.5 * 1.5 \mathrm{~d} 1=17.94 \mathrm{~mm}$ 


\section{Where,}

Design bearing pressure for small end pb1=12.5 to $15.4 \mathrm{~N} /$ $\mathrm{mm} 2$

Length of the piston pin $11=(1.5$ to 2$) \mathrm{d} 1$

Outer diameter of the small end $=\mathrm{d} 1+2 \mathrm{tb}+2 \mathrm{tm}=17.94+[2 * 2]$ $+[2 * 5]=31.94 \mathrm{~mm}$ where,

Thickness of the bush (tb) $=2$ to $5 \mathrm{~mm}$

Marginal thickness $(\mathrm{tm})=5$ to $15 \mathrm{~mm}$

Inner diameter of the big end $\mathrm{d} 2=23.88 \mathrm{~mm}$ where,

Design bearing pressure for big end pb2 $=10.8$

to $12.6 \mathrm{~N} / \mathrm{mm}$

Length of the crank pin $12=(1.0$ to 1.25$) \mathrm{d} 2$

Root diameter of the bolt $=((2 \mathrm{Fim})(\pi * \mathrm{St})) 1 / 2=$ $(2 * 6277.167 \pi * 56.667) 1 / 2=4 \mathrm{~mm}$

Outer diameter of the big end $=\mathrm{d} 2+2 \mathrm{tb}+2 \mathrm{db}+2 \mathrm{tm}=$ $23.88+2 * 2+2 * 4+2 * 5=47.72 \mathrm{~mm}$ where,

Thickness of the bush $[\mathrm{tb}]=2$ to $5 \mathrm{~mm}$

Marginal thickness $[\mathrm{tm}]=5$ to $15 \mathrm{~mm}$

Nominal diameter of bolt $[\mathrm{db}]=1.2 \mathrm{x}$ root diameter of the bolt $=1.2 \times 4=4.8 \mathrm{~mm}$

Height at the big end (crank end) $=\mathrm{H} 2=1.1 \mathrm{H}$ to $1.25 \mathrm{H}=17.6$ $\mathrm{mm}$

Height at the small end (piston end) $=\mathrm{H} 1=0.9 \mathrm{H}-0.75 \mathrm{H}=14.4$ $\mathrm{mm}$

\section{MODELING AND ANALYSIS OF CONNECTING ROD}

\section{Modelling of Connecting Rod (Solid Works):}

Step 1: - Opened Solid Works Software.

Step 2: - Selected MODEL option.

Step 3: - Gave the software the location to save the file.

Step 4: - Selected the SKETCH option.

Step 5: - Selected the suitable plane for sketching the connecting rod. (YZ Plane).

Step 6: - Selected the CIRCLE option and drew a circle (Circle 1). (Inner dia. Of big end - 23.88).
Step 7: - Again selected the CIRCLE option and drew a circle (Circle 2) for the same centre as that of previous circle (Outer dia. Of big end - 47.72)

Step 8: - Selected the LINE option and drew a line (Centre line) from centre or the circle.

Step 9: - Again selected the CIRCLE option and drew a circle (Circle 3) at the other end of the previously drawn line. (Inner dia. Of small end - 17.94).

Step 10: - Drew another circle (Circle 4) on the centre of (Circle 3). (Outer dia. Of small end 31.94).

Step 11: - Selected the LINE option and drew two parallel lines on both sides of the previously drawn line. (Distance between centre line and parallel lines - 8 each).

Step 12: - Followed the same steps and drew a rectangular slot between the upper circles and lower circles. (Thickness -8 , Height - 40)

Step 13: - Selected the TRIM option and trimmed the unwanted lines.

Step 14: - Clicked on the FINISH SKETCH option.

Step 15: - Selected the EXTRUDE option and selected the lower circle and extruded it symmetrically. (Height of big end $-17.6)$.

Step 16: - Similarly extruded all the components of the connecting rod symmetrically. (Height of small end - 14.4, Height of the section - 16, Height of the slot -3.2).

Step 17: - United every component with each other.

Step 18: - Selected the SHOW AND HIDE option and hide the sketches, datum planes, coordinate system, etc.

Step 19: - Saved the Model using SAVE option.

Step 20: - Again selected the SAVE option and saved the model in IGES format for further analysis on ANSYS Software.

\section{$>$ Static Analysis}

Static analysis deals with the conditions of equilibrium of the bodies acted upon by forces.

A static analysis can be either linear or nonlinear. All types of non-linearities are allowed such as large deformations, plasticity, creep, stress stiffening, contact elements etc. this chapter focuses on static analysis. A static analysis calculates the effects of steady loading conditions on a structure, while ignoring inertia and damping effects, such as those carried by time varying loads. A static analysis is used to determine the displacements, stresses, strains and forces in structures or components caused by loads that do not induce significant 
inertia and damping effects. A static analysis can however include steady inertia loads such as gravity, spinning and time varying loads. In static analysis loading and response conditions are assumed, that is the loads, and the structure responses are assumed to vary slowly with respect to time. The kinds of loading that can be applied in static analysis includes,

a) Externally applied forces, moments and pressures

b) Steady state inertial forces such as gravity and spinning

c) Imposed non-zero displacements

A static analysis result of structural displacements, stresses and strains and forces in structures for components caused by loads will give a clear idea about whether the structure or components will withstand for the applied maximum forces. If the stress values obtained in this analysis crosses the allowable values, it will result in the failure of the structure in the static condition itself. To avoid such a failure, this analysis is necessary. Following is the procedure to carry out static structural analysis:

1. Started Ansys Workbench.

2. Double clicked on Static Structural in the toolbox window to add it to the Project Schematic window.

3. Renamed the Static Structural analysis system as "Connecting Rod".

4. In the connecting rod analysis system, we double clicked the "Geometry" cell; the

"Design Modeler" window along with the ANSYS Workbench dialog box is displayed.

5. Set the units to Millimetre and imported the external geometry file of connecting rod which we designed in SOLID WORKS software.

6. Exit the "Design Modeler" window.

7. Then we defined "Engineering Data". In this section material for the current project is assigned. In ANSYS by default structural steel is selected. To assign new material we turned on the engineering data source. Then we generated new library for connecting rod and made a tick mark on the new generated library named connecting rod to convert it into edit mode. After this, we added different five materials which are kept under study. After giving all required properties for connecting rod we saved them into the library. In the same way we saved the information about all consideration and then added all the five materials in the content by clicking on the plus sign.

8. After importing the external geometry, we meshed the connecting rod. Meshing is done for better accuracy in result.
9. After Meshing we double clicked the "Setup" cell, where we provided fixed support and Load (Force) on connecting rod.

10. After providing force and fixed support to the connecting rod, we double clicked the "Solution" cell; where the solutions to be obtained from ANSYS Workbench was found.

11. Then the various results such as equivalent stress, maximum stress, and deformation were obtained.

\section{RESULT AND DISCUSSION:}

Static analysis as per the given procedure above was used for the analysis of the connecting rod. All materials listed in the above chapter were analysed.

\section{CONCLUSION AND FUTURE SCOPE}

1. Solid modelling of connecting rod was made in NX 10 according to design procedure used and analysis under the effect of tensile and compressive loads in terms of pressure is done in ANSYS Workbench.

2. From analysis it is observed that the minimum stresses among all loading conditions, were found at crank end cap as well as at piston end. So the material can be reduced from those portions, thereby reducing material cost.

3. For further optimization of material dynamic analysis of connecting rod is needed. After considering dynamic load conditions once again finite element analysis will have to be performed. It will give more accurate results than existing.

4. From the static analysis the stress is found maximum at the small end of the connecting rod.

5. Aluminium alloy connecting rod is having more weight and displacement than magnesium and beryllium alloys. So, aluminium connecting rod shows more shaky behaviour.

6. Maximum von mises stress, Maximum von mises strain and Maximum displacement are minimum in connecting rod of Beryllium alloy. 7. Other than conventional materials used the above studied material can be also used as they show greater quality than the conventional material.

8. The only thing that is barrier to implement of above materials is costing, availability of material and its repairing.

\section{Future Scope}

The above work is presented on static analysis of connecting rod and has many aspects to research further as follows

1. Torsional analysis can be done due to presence of small amount of torsional moment at the end points. 
2. Design modification can be done to minimize the weight of connecting rod and the inertia force.

3. Work on the internal coating of hard material inside both ends can be done to minimize the wear failure in connecting rod.

4. Development of connecting rod using different techniques and above stated materials can be manufactured and experimental and dynamic analysis can be carried out.

5. Fatigue analysis can also be carried out on material having high quality and cost to improve and define life of connecting rod

\section{References:}

1.Webster, W.D, Coffell R, and Alfaro D, 1983, “A 3Dimensional Finite Element Analysis of a highspeed Diesel Engine Connecting Rod", SAE technical paper series, paper no. 831322 .

2.Repgen, B, 1998, “Optimized connecting Rods to Enable Higher Engine performance and

Cost Reduction". SAE Technical Paper Series, Paper no. 980882.

3.Kuldeep B, Arun L R, Mohammad Faheem,

"Analysis and Optimization of connecting rod using ALFASiC Composite", International Journal of Innovative Research in Science Engineering and Technology Vol 2, Issue 6,June 2013.

4.Mr. H. B. Ramani, Mr. Neeraj Kumar, Mr. P.M. Kasundra, Analysis of Connecting Rod under Different Loading Condition Using Ansys Software. International Journal of Engineering Research \& Technology (IJERT) Vol. 1 Issue 9, November- 2012 ISSN: 2278- 0181.

5.DR.B.K.Roy ,"Design Analysis and Optimization of Various Parameters of

Connecting Rod using CAE Softwares," International Journal of New Innovations in Engineering and Technology (IJNIET), Vol. 1 Issue 1 October 2012, ISSN: 2319-6319,Page no,52 64 .

6.Pravardhan S. Shenoy and Ali Fatemi, "Connecting Rod Optimization for Weight and Cost Reduction," 2005 SAE International.

7.Shahrukh Shamim, "Design and comparative analysis of connecting rod using finite element method," International Journal of Engineering Research \& Technology (IJERT), Vol. 3 Issue 9, September- 2014. 